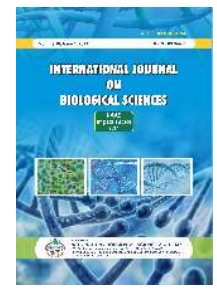

\title{
STANDARDIZATION AND EVALUATION OF ANTIBODY RESPONSE BY PLATE-ELISA FOR THE DETECTION OF PARAMPHISTOMOSIS IN RUMINANTS
}

\author{
Syed Shabih Hassan \\ Department of Veterinary Parasitology, College of Veterinary Science \\ Guru Angad Dev Veterinary and Animal Sciences University, Ludhiana - 141004, Punjab, India
}

\section{Research Paper}

Received: 20.10.2020

Revised: 28.10.2020

Accepted: 10.11.2020

\begin{abstract}
Disease transmission, diagnosis and preventive measures have become a major concern for the scientists working in national and international institution throughout the world. Paramphistomosis is a parasitic disease occurring in domestic ruminants causing economic loss to livestock industry. Early diagnosis of the disease is very important so that the loss due to disease can be curtailed by the appropriate treatment. Immunodiagnostic assays are helpful in the diagnosis of parasitic diseases. Hence immunological tests especially microtitre plate enzyme linked immunosorbant assay (ELISA) are the mainstay of diagnosis. Enzyme linked immunosorbant assay (ELISA), one of the immunodiagnostic assays is helpful in the diagnosis of paramphistomosis. More than 500 clinical/field sera samples of buffaloes, goats, sheep and cattle were collected from Bareilly, Delhi, Dehradun and Ludhiana under DST (GOI) sponsored project. Microtitre plate (Greiner) containing 96 well for Indirect Plate-ELISA was standardized for the detection of anti-Paramphistomunepiclitum antibodies in immunized rabbit using somatic antigen of P.epiclitum ranging from $1 \mu \mathrm{g} / \mathrm{ml}$ to $10 \mu \mathrm{g} / \mathrm{ml}$, HRPO conjugate dilutions 1:1000 to 1:8000 and the range of sera dilution from 1:50 to 1:1,60,000. The optimum concentration of adult somatic P. epiclitum antigen was observed to be $2 \mu \mathrm{g} / \mathrm{ml}$, conjugate dilution 1:1000 and sera dilution at 1:200 and 1:400. A total of 222 clinical/field sera samples of ruminants were tested. Out of the total 106 ruminant samples were found to be positive with the incidence rate of $47.75 \%$. The highest percent positivity ( $84.0 \%$ ) was found in naturally infected buffaloes followed by $26.25 \%$ in goats and $12.5 \%$ in sheep by indirect plate-ELISA. The observations on sensitivity and specificity of plate-ELISA test and immune response of antiP.epiclitum antibodies in experimental animal were also evaluated. The observation of high titre during the study is very effective for the detection of anti-P.epiclitum antibodies in field survey or in clinical cases. It is also helpful in the characterization of immunodominant antigens for the immunological control of the disease. Hence, indirect plateELISA is very important for the detection of paramphistomosis in domestic ruminants in early stages.
\end{abstract}

Keywords: Paramphistomosis, Detection, Antigen, Plate-ELISA, Anti-P.epiclitum antibodies, Ruminants.

\section{INTRODUCTION}

Historically, it is evident that management measures to prevent, control, eliminate or eradicate diseases have always attracted considerable attention in veterinary practice for the sake of economy. Transmission of parasitic diseases, its diagnosis and control have become a major concern throughout the world. Among the different snail borne infections, paramphistomosis caused by Paramphistomumepiclitum, is a major cause of morbidity, mortality and decreased productivity in cattle, buffaloes, goats and sheep resulting in serious economic losses in endemic areas. Paramphistomosis is one of the most pathogenic disease in domesticated animals causing heavy economic losses to the livestock industry to the tune of several thousand crores of rupees annually. Paramphistomosis is a group of disease caused by the various species of parasites; Paramphistomumepiclitum, $P$. cervi and Gastrothylaxcrumenifer are found to be

*Corresponding author: fish_ab@rediffmail.com 
predominant in domestic ruminants. Immature flukes which inhabit the duodenum, where massive infections may cause severe enteritis and mortality may go up to 20-40\% (Dutt, 1980). The disease is a major concern in low-lying areas as the snail population viz. Indoplanorbisexustus and Gyraulusconvexiusculus (intermediate host in the life cycle of paramphistome) increases mainly during monsoon and post monsoon season, which is characterized by sporadic epizootics of acute gastroenteritis with high morbidity and mortality in young domestic animals. Immature parasites are predominant in dorsal and ventral sacs of rumen of buffaloes, sheep and goats (Varma et al, 1989). Incidence of amphistomosis in cattle, buffaloes, sheep and goat has been reported in different states of India from time to time (Chhabra et al., 1972; Chhabra and Gill, 1975; Gupta et al., 1978; Panda \&Misra, 1980;Varma et al., 1989; Manna et al., 1994; Saheb \& Hafeez, 1995; Sivajothi\& Reddy 2014;Chaudhary et al., 2014 and Bhanot\& Gupta, 2019). Misraet al. (1996) reported that paramphistome infected lambs showed significant reduction in $\mathrm{Hb}$ (g\%) and PCV (\%) and severe lecucocytosis. Bhongadeet al. (1993) recorded decreased level of haemoglobin in animals suffering from helminthic parasitic disease. The rate of paramphistomosis incidence was recorded to be highest in buffaloes $5.42 \%$ followed by cattle, sheep and goats in Punjab (Hassan et al, 2005). The disease is widely prevalent in India resulting in heavy losses in terms of mortality, morbidity, reduced wool, meat, milk production, reproductive disorders and expenditure on the purchase of antiparasitic drugs. Dunn (1969) reported most of outbreaks in sheep and goats are due to transmission of infection through bovines. In general the parasitic diseases cause great economic losses. Scientific literature highlighted that more than 500 million cattle worldwide are at risk (Ristic, 1988). In India which accounts for $51 \%$ of Asia and about $19 \%$ of world bovine population (Kadiravel, 2002), the death rate due to immature paramphistomosis is very high and may go up to $80-90 \%$ in young ruminants. Punjab produces more than 10 percent of the total milk production in the country. The economy losses in livestock due to disease differ from season to season (Singh et al., 1983). Santra and Pachalag (1996) estimated the economic losses due to various types of livestock disease, among all diarrhoea caused maximum (59.42\%) losses. The morbidity and mortality of animal due to various types of parasitic diseases in domestic animals like cattle, buffalo, sheep and goats caused by the immature flukes belonging to the family Paramphistomidae. All the species are not pathogenic. Several clinical outbreaks of paramphistomes proved that the species particularly Paramphistomumepiclitum, P. cervi, Gastrothylax crumenifer, Gigantocotyle explanatum, Cotylophoron cotylophorum and Fischoederius elongatus were found to be predominant in domestic ruminants. The other amphistome species viz. Cotylophoron bareilliensis and C. indicum found in sheep, C. bareilliensis in goats and P. dutti, Duttielacephaloporus, Olveriabosi and $O$. indica found in buffaloes (Prasad and Varma, 1999).

The conventional method of diagnosis by coprological examination to detect light infection during subclinical phase is difficult due to prolonged prepatency. So besides chemotherapeutic control, attention is being laid on early and accurate immunodiagnosis of the disease. ELISA is being practiced as the most effective diagnostic technique for detection of anti-parasitic antibodies. However, immunodiagnostic assays also have their own limitations in terms of non-specificity and cross-reactivity. With this view point in mind, the study was undertaken to employ plate-ELISA diagnostic techniques for paramphistomosis with increased sensitivity and specificity. The early detection of the disease and its diagnosis during subclinical phase is of utmost importance so that the mortality can be reduced by timely treatment of the disease.

\section{MATERIALSAND METHODS}

Live flukes were collected from rumen of slaughtered goats, sheep and buffaloes from slaughter houses in Bareilly, Delhi, Dehradun and Ludhiana. The collected parasites were washed thoroughly in normal saline and then stored at $-20 \mathrm{C}$ till further use.

\section{Preparation of Antigen}

The collected parasites were washed thoroughly in normal saline and homogenized in 0.1 M PBS (pH 7.4) and sonicated in Soniprep 150 at 10 (amplitude) for 8 min (4 cycles of 2 minute each). The homogenate was then centrifuged at $15000 \mathrm{rpm}$ for $15 \mathrm{~min}$ at $4^{\circ} \mathrm{C}$. The supernatant obtained was filtered through $0.22 \mathrm{~m}$ Millex GV filter and stored in small aliquots of $0.5 \mathrm{ml}$ each at $-20{ }^{\circ} \mathrm{C}$, after protein estimation by Lowry et al (1951). The collected filtrate was used as antigen for immunodiagnostic tests.

\section{Production of Antibodies in rabbits}

The New Zealand white rabbits were acclimatized in the laboratory for 15 days before starting the experiment. They were immunized subcutaneous with $400 \mathrm{~g}$ of $P$. epiclitumsomatic antigen mixed with Freund's Complete Adjuvant (FCA). This was followed by booster dose of Ag with FIA (Freund's Incomplete Adjuvant) after an interval of 7days and then immunized the rabbit with $400 \mathrm{~g}$ of the antigen alone after an interval of 7 days till desired Ab titre obtained. 
The animals were bled before starting the experiment for collection of pre-immune sera to be used as control and also before each booster immunization and the serum was refrigerated at $-20^{\circ} \mathrm{C}$ till use.

\section{Metacercariae}

Theparamphistomeinfectedsnailswerekeptseparatelyf orharvestingmetacercariae. Metacercariae of Paramphistomumepiclitum were harvested on polythene sheets, plastic tray, leaves from Indoplanorbisexustus, Gyraulus convexiusculus Lymnaeaspp snails (intermediate host) maintained under laboratory conditions. These were processed and stored at $10^{\circ} \mathrm{C}$ in tapwater until use. The viability of each batch was microscopically tested prior to oral administration of infection dose to the animals as per plan.

\section{Sheep}

Six sheep below one year old were procured from LPM department and local market. Animals were kept in the experimental animal shed of the College of Veterinary Sciences providing ad lib food and water as per the guideline of animal ethical committee. The faeces of the animals were examined by sedimentation and floatation methods. Upon examination, all the animals were treated with anti-Paramphistomedeworming drug, Albendazole @ 7.5 mg/kg body weight for making animals free from infection.

\section{Production of Antibodies in sheep:}

For raising experimentally infected sheep sera, paramphisto memetacercariae were collected for experimental production of disease in sheep after exposing the snails against artificial light and sunlight. The metacercariae were collected and counted. Of which, 4000 metacercariae were given to four sheep individually for raising paramphistome infection in experimental condition. The animal was starved for 12 hours before giving the infection. Metacercariae was kept in small quantity of water in a glass tube then transferred in glass syringe and poured into the oral cavity. Faecal samples examined microscopically and found positive for paramphistome eggs after 135 days post infection. Serological samples were collected twice in a week for plate-ELISA immunodiagnostic tests with various kind of paramphistomeantigen.

\section{Positive and negative reference sera}

Sera of four sheep heavily infected with Paramphistomumepiclitum were chosen as positive reference sera. Negative sera were collected from 10 uninfected animals maintained in the experimental animal shed of the Department of Veterinary Parasitology, GADVASU, Ludhiana.

\section{Detection of Antibodies by plate-Enzyme linked Immunosorbent Assay}

Indirect plate-ELISA was standardized using somatic $P$. epiclitumantigen concentration ranging from 2-10 $\mathrm{g} / \mathrm{ml}$, confirmed positive bovine and ovine sera and rabbit raised anti-species HRPO conjugate in different dilution ranges. ELISA plate was coated with $100 \mathrm{l}$ of somatic antigen $(2 \mathrm{~g} / \mathrm{ml})$ and kept overnight at $4 \mathrm{oC}$. PBS-T (0.05\%) was used for washing the plate thrice a time and dried by automated MK-2 plate washer. 2\% lactogen in PBS (0.01M) was used for blocking the plate and incubated at $37^{\circ} \mathrm{C}$ for $1 \mathrm{~h}$. After washing, $50 \mathrm{l}$ serum sample (1:400 and 1:800 dilution) was added and incubated for $1 \mathrm{~h}$ at $37^{\circ} \mathrm{C}$ and then rabbit antispecies HRPO conjugate for $1 \mathrm{~h}$ at the same temperature. After proper washing, OPD substrate was used and the interval of $10 \mathrm{~min}$ the reaction was stopped by adding $\mathrm{H}_{2} \mathrm{SO}_{4}$. Lastly, OD of the plate was read by ELISA Reader at $492 \mathrm{~nm}$.

Polyclonal antibodies were tested and found positive by Plate-ELISA using $P$. epiclitumsomatic antigen. The test antigen was diluted to concentration between $10 \mathrm{~g} / \mathrm{l}$ to $10 \mathrm{ng} / \mathrm{l}$. The dilution range of sera was used between $1: 100$ to $1: 80000$.

\section{RESULTS AND DISCUSSION}

\section{Employment of Indirect Plate-ELISA for the detection of anti-P.epiclitum antibodies}

The adult $P$. epiclitum was collected from rumen of slaughtered goat, sheep and buffaloes from slaughterhouse at Bareilly, Delhi, Dehradun and Ludhiana. The parasite collected were thoroughly washed in normal saline and processed separately for antigen preparation. Parasites were homogenized in 0.1 M PBS ( $\mathrm{pH}=7.4$ ) sonicated in soniprep-150 for 8 min in four cycles each cycle of $2 \mathrm{~min}$ and centrifuged at 3000rpm for $10 \mathrm{~min}$. The supernatant was filtered through 0.22 um Millex GV filters and stored at $-20^{\circ} \mathrm{C}$, which was used as adult somatic antigen for indirect plate-ELISA test.

The sera of experimental rabbits immunized by somatic antigen of $P$. epiclitum and experimentally infected sheep sera and as well as clinical/field sera were used against somatic and purified antigen of $P$. epiclitum through a specific technique of plate-ELISA for knowing the immune response and immunoreactive patterns and titre of the different sera. 
Indirect-Plate ELISA was standardized using adult somatic antigen of $P$. epiclitum ranging from $1 \mu \mathrm{g} / \mathrm{ml}$ to $10 \mathrm{ug} / \mathrm{ml}$, goat anti-rabbit HRPO conjugate dilutions ranging from $1: 1000$ to $1: 8000$ and the range of sera dilution from $1: 50$ to $1: 1,60,000$.

During the experiment 2\% lactogen was used for blocking the non-specific antigen binding sites following three washings with PBS Tween-20 (0.1\%) for $5 \mathrm{~min}$ each. After that plate was incubated in sera dilutions followed by anti-species HRPO conjugate and then substrate orthophenylene diamine dihydrochloride (OPD) @ 10mg/25ml working phosphate citrate buffer $+12 \mu \mathrm{l}\left(30 \% \mathrm{H}_{2} \mathrm{O}_{2}\right)$. Finally the reaction was stopped using $0.1 \mathrm{M} \mathrm{H}_{2} \mathrm{SO}_{4}$ and OD of the ELISA experiment was read at $492 \mathrm{~nm}$.

The optimum concentration of adult somatic $P$. epiclitum antigen was observed to be $2 \mu \mathrm{g} / \mathrm{ml}$, conjugate dilution 1:1000 and sera dilution at 1:200 and 1:400.
Indirect plate-ELISA with hyperimmune sera using adult somatic $P$. epiclitum antigen

The mean OD value of rabbit No. 1626, 1627 and 1685 were ranged between $0.82-2.082,0.76-2.146$, and $1.03-2.16$ at sera dilution $1: 200$ where as $0.445-$ 2.126, $0.69-2.211$, and $0.74-1.749$ at sera dilution 1:400 respectively. Highest peak OD values in the sera of rabbit No. 1626, 1627 and 1685 were observed after $5^{\text {th }}, 12^{\text {th }}$ and $4^{\text {th }}$ week respectively (Fig. 1 ). The antibody level decreased after $6^{\text {th }}, 13^{\text {th }}$ and $5^{\text {th }}$ week in rabbit No. 1626, 1627 and 1685 respectively.

\section{Indirect plate-ELISA with hyperimmune sera} using adult somatic $G$. crumeniferantigen

The mean OD value of rabbit No. 1626, 1627 and 1685 were ranged between, $0.61-2.47,0.923-2.635$ and $0.605-2.771$ at sera dilution 1:200 where as $0.543-$ 2.334, $0.767-2.364$, and $0.586-2.249$ at sera dilution 1:400 respectively. Highest peak OD values in the sera of rabbit No. 1626, 1627 and 1685 were observed after $10^{\text {th }}, 12^{\text {th }}$ and $5^{\text {th }}$ week respectively (Fig.1). The antibody level decreased after $11^{\text {th }}, 13^{\text {th }}$ and $6^{\text {th }}$ week in rabbit No. 1626, 1627 and 1685 respectively.

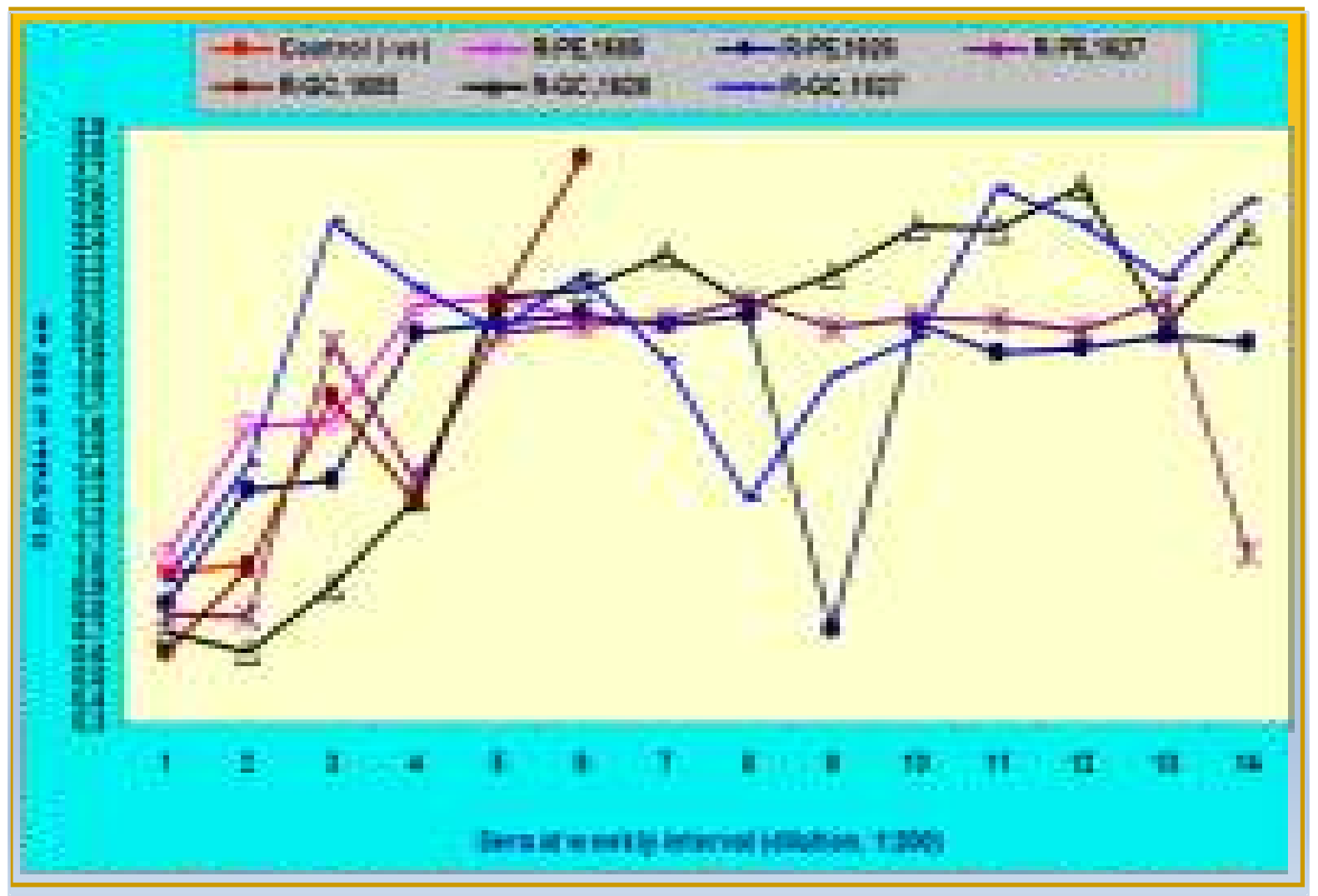

Fig. 1: Immune response of rabbits in ELISA using HIS (1:200) with somatic P. epiclitum and $G$. crumenifer antigen. 
Indirect plate-ELISA with experimental sheep sera using adult somatic $P$. epiclitum antigen: The experimental sera of all four sheep were used against somatic antigen of $P$. epiclitum for knowing the immune response of the sheep sera. Serially diluted $1: 50$ to $1: 1,60,000$ serum of experimentally infected and control sera was subjected with somatic antigen of $P$. epiclitum in triplicate wells. A pattern of antibody response was assessed at weekly interval till the end of experiment.

Higher dilution i.e. 1:200 and 1:400 was considered for exploring the non-specific reaction by antibodies and interpretation of the findings. The comparison was made between infected and control sera. The OD value of infected group was observed to be higher than control.

The mean OD value of sheep No. 61, 3142, 66, 450, 452 and 470 were ranged between $0.748-1.36,0.782-$ 1.695, $0.971-1.632,0.621-0.896,0.785-1.085$ and $0.688-0.872$ at sera dilution $1: 200$ respectively.

Highest peak OD values in the sera of sheep No. 61, 3142, 66, 450, 452 and 470 were observed after $11^{\text {th }}$ week post infection (wpi), $7^{\text {th }} \mathrm{wpi}, 4^{\text {th }} \mathrm{wpi}, 3^{\text {rd }} \mathrm{wpi}$, $16^{\text {th }}$ wpi, and $16^{\text {th }}$ wpirespectively (Fig.2). The antibody level decreased after $12^{\text {th }}, 8^{\text {th }}, 5^{\text {th }}, 4^{\text {th }}, 17^{\text {th }}$, and $17^{\text {th }}$ week in sheep No. 61, 3142, 66, 450, 452 and 470 respectively.

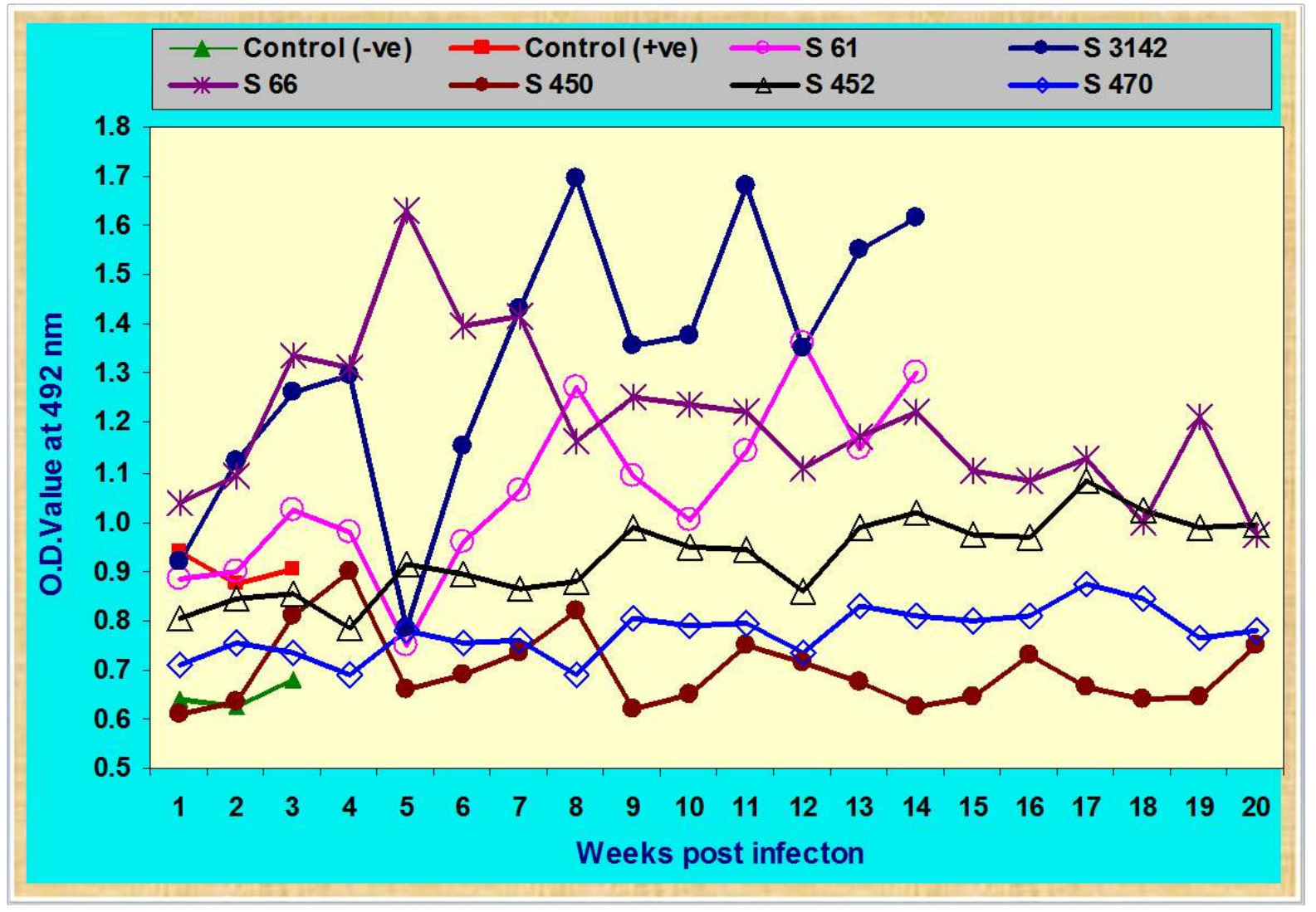

Fig. 2: Immune response of experimental sheep sera in ELISA using somatic antigen of P. epiclitum.

\section{Indirect Plate-ELISA with Clinical/Field Sera:}

A total of 222 sera samples (94 buffaloes, 80 goats and 48 sheep) were examined by indirect plate-ELISA. Various negative and positive controls were included. Out of the total examined sera 106 samples (79 Buffaloes, 21 goats and 6 sheep) were found to be positive with the incidence rate of $47.75 \%$. The highest percent positivity (84.0\%) was found in buffaloes followed by $26.25 \%$ in goats and $12.5 \%$ in sheep. The observation for the detection of paramphistome infection in 222 clinical/field sera samples by indirect plate-ELISA is depicted in Table 1 and Fig.-3. 
Table 1: Paramphistome antibodies detection by Plate-ELISA in field cases.

\begin{tabular}{|l|c|c|c|}
\hline Animal Sera & No. Examined & No. Positive & Percent (\%) positivity \\
\hline Buffaloes & 94 & 79 & 84.0 \\
\hline Sheep & 48 & 6 & 12.5 \\
\hline Goats & 80 & 21 & 26.25 \\
\hline Total & 222 & 106 & 47.75 \\
\hline
\end{tabular}

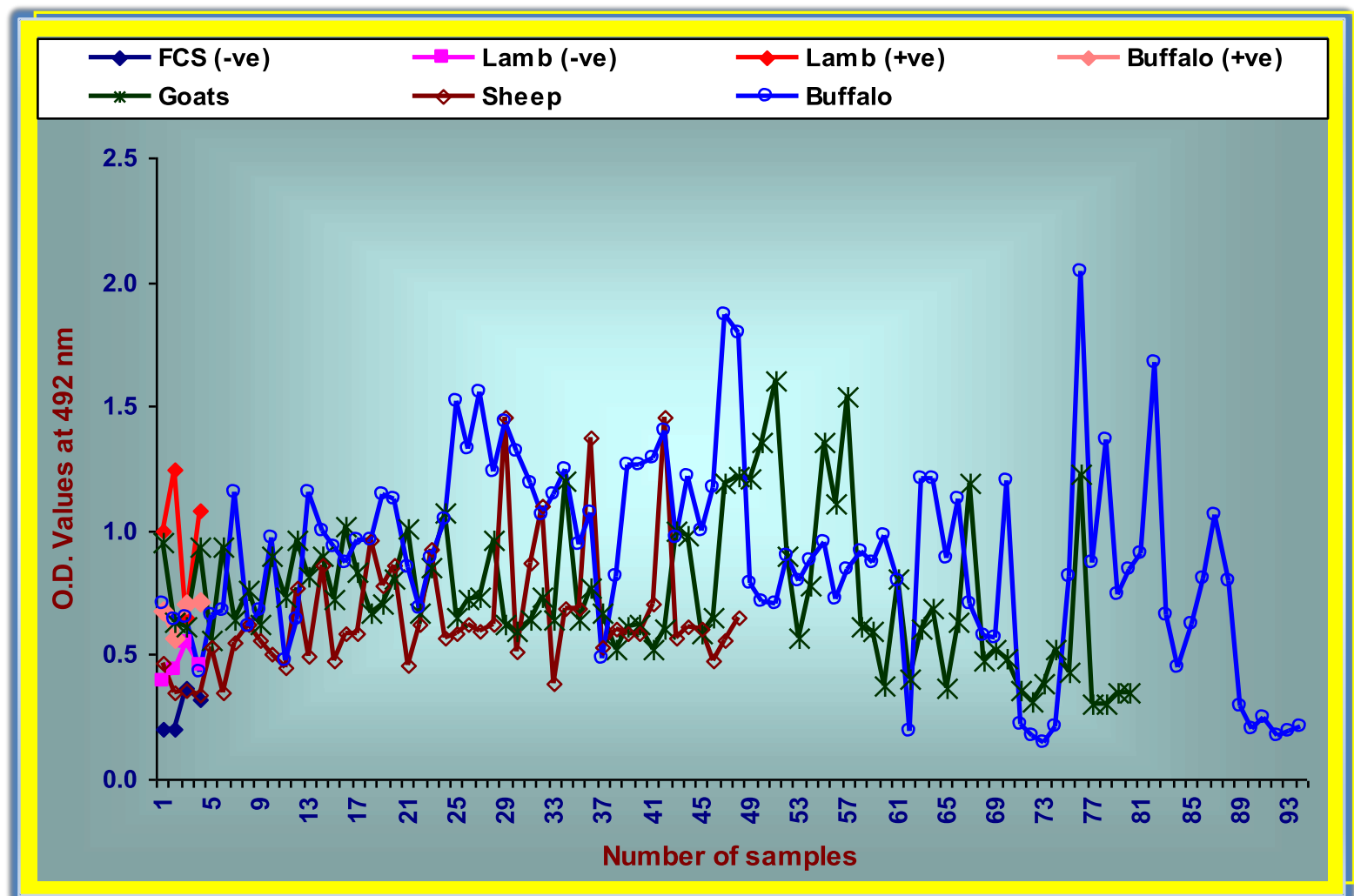

Fig. 3: Evaluation of field/clinical sera samples against somatic $P$. epiclitum antigen by Plate-ELISA at sera dilution 1:200.

ELISA is being practiced as the most effective diagnostic technique for detection of anti-parasitic antibodies. ELISA especially Dot-ELISA has been observed as a specific and sensitive serodiagnostic method for Paragonimosis sp. (Zhang et al. 2000). It is a fast, simple and inexpensive test and also found suitable for field diagnosis of fasciolosis in cattle. The test showed a sensitivity of $82 \%$, specificity of $90 \%$ with 95\% confidence level (CL), good repeatability and a significant association with reference to ELISA (Maisonnave, 1999). Furthermore in comparison to diffusion in gel (DIG) ELISA and indirect ELISA tests, Dot ELISA (with sensitivity of $93.1 \%$ and specificity 95.4\%) has been found to be highly effective and may be recommended for use in sero-epidemiological surveys of F. hepatica (Ibarra et al.1998). ELISA has also been observed to be suitable for widespread use in the diagnosis of cryptosporidiosis (El-Shazly-AM et al.2002). In Haemonchus contortus also a high titre of 1:40000 were observed with rabbit hyperimmune sera raised against somatic antigen of $H$. contortus (Kaur et al. 2002a, b). It has been found that false positive and false negative results in other diagnostic assays can often be resolved by immunoblotting (Molinaet al. 1993).ELISA are preferably used for the diagnosis of infection with amphistome fluke due to their ease and the ability to test large numbers of samples. Now a days, ELISA have been optimised to detect of host 
antibodies in serum using whole excretory-secretory antigen. However, there are many excretorysecretoryproducts based ELISA presently reported in the manuscript. Small number have been evaluated for use in the field conditions. Salimi-Bejestani et al. 2005; Kuerpick, et al. 2013 have reported sensitivities of between 86-100\% and specificities between 70 $99 \%$. However, the use of native antigens in commercial diagnostic tests are not ideal as they rely on a regular supply of amphistomefluke from the slaughter houses. Rojas et al. (2014) revealed aboutbatch to batch variation between preparations of excretory-secretory antigens, leading to inconsistencies in the quality and amount of antigens present in the batch. ELISA showed high sensitivity due to cross reactivity among related species of trematodes there is a need for purification of antigenic moieties to acquire more specific result. Percentage prevalence by ELISA in different animals revealed that the early diagnosis is very important for curtailing the loss due to disease by appropriate treatment. Hence the high titre observed in the present study may prove to be of great significance in diagnosis of paramphistomosis in field cases for the immunological control of the disease. The application of ELISA diagnostics against paramphistomosis in domestic ruminants is very sensitive and specific.

\section{CONCLUSION}

Paramphistomosis is a pathogenic disease in domesticated animals causing morbidity and mortality in livestock industry. The control of disease will benefit the farmers in terms of economic status. The sera of anti$P$. epiclitum and experimental sheep can be used as reference sera with paramphistome antigens for immunodiagnosis of paramphistomosis. Immature flukes causing paramphistomosis was identified through the dynamics of serodiagnostic tests in domestic ruminants. Immunodiagnostic tests such as plate-ELISA are very sensitive tests and useful for the detection of paramphistome antibodies in clinical field cases. These observations are very important for the diagnosis of paramphistomosis and immunological control of the disease occurring in livestock industry. The mortality of animal due to paramphistomosis may be significantly reduced by detecting infection at the earliest.

\section{ACKNOWLEDGEMENTS}

Author is thankful to Science \& Engineering Research Council, Department of Science \& Technology, Ministry of Science \& Technology, Govt. of India New Delhi for financial support in the form of DST-SERCFAST-Track project and Guru Angad Dev Veterinary and Animal Sciences University, Ludhiana, for facilities provided.

\section{REFERENCES}

1. Bhanot, V. and Gupta, R. (2019) Occurrence of paramphistomosis in cattle and buffaloes with digestive disorders in ambala district of Haryana. Haryana Vet. (Dec., 2019), 58 (2): 298-300.

2. Bhongade, H.G., Sarode, D.B., Rode, A. M. and Sapre, V.A. (1993) Effect of anthelmintic therapy on haematobiochemical profiles of dairy cows. Indian J. Vet. Med., 13:75-76.

3. Chaudhary, S., Vatsya, S. and Yadav, C. L. (2014) Epidemiology of paramphistomiosis in domestic ruminants of Garhwal region of Uttarakhand, India. Veterinary Research International, Jakraya Publications (P) Ltd. 2 (1): 12-14.

4. Chhabra, R. C., Kwatra, M. S. and Bali, H. S. (1972) Immature paramphistomiasis in Sahiwal and crossbred calves in Punjab. Indian Journal of Animal Sciences, 42 (4), 272-74.

5. Chhabra, R. C. and Gill, B. S. (1975) Incidence of helminthic infections and control of amphistomiasis and fascioliasis in animals in two villages of the Punjab. Journal of Research, PAU, 12, 184-188.

6. Dunn, M. A. (1969) Veterinary Helminthology. William Heinemann Medical Books Ltd., London pp.165.

7. Dutt, S.C. (1980)Paramphistomes and Paramphistomiasis of Domestic Ruminants in India, Punjab Agricultural University Publication, Ludhiana.

8. El-Shazly, A.M., Gabr-A., Mahmoud, M.S.E., Aziz-S.S. A and Saleh, W.A. (2002) The use of Ziehlneelsen stain, ELISA and nested PCR in diagnosis of cryptosporidiosis in immunocompetent - compromised patients. Journal of Egyptian Society of Parasitology, 32 (1) $155-166$.

9. Gupta, P. P., Balwant Singh and Dutt, S. C. (1978) A note on amphistomiasis in an adult. Buffalo. Indian Veterinary Journal, 55, 491-92.

10. Hassan, S. S., Kaur, K., Joshi K. and Juyal P. D. (2005) Epidemiology of paramphistomosis in domestic ruminants in different district of Punjab and other adjoining areas. Journal of Veterinary Parasitology, 19 (1), 43-46. 
11. Ibarra, F., Montenegro, N., Vera, Y., Boulard, C., Quiroz, H., Flores, J and Ochoa, P. (1998) Comparisonof three ELISA tests for seroepidemiology of bovine fasciolosis. Veterinary Parasitology, 77 (4) 229-236.

12. Kadiravel, R. (2002) Limited investment but consistent growth. In: Survey of Indian Agriculture, The Hindu, Kasthuri publications, Chennai, pp.147-150.

13. Kaur, K., Kapur, J., Parmar, A. and Sood, M. L. (2002a) Kinetics of antibody response by Dot ELISA in rabbits immunized with adult Haemonchus contortus antigen. Parasite, 9, 363365.

14. Kaur, K., Kapur, J., Parmar, A. and Sood, M. L. (2002b) Identification of immunodominant antigen of adult Haemonchuscontortus (Nematoda: Trichostrongylidae). J. Vet. Med., B 49, 260-262.

15. Kuerpick, B. et al. (2013) 'Evaluation of a recombinant cathepsin L1 ELISA and comparison with the Pourquier and ES ELISA for the detection of antibodies against Fasciola hepatica', Veterinary Parasitology. 193(1-3), pp. 206-213.

16. Lowry, O. H., Rosbrought, N. J., Farr, A. L. and Randall, R. J. (1951) Protein measurement with the folin phenol reagent. J. Biol. Chem., 193, 265275.

17. Manna, A. K., Pramanik, S. and Mukherjee G. S. (1994) Incidence of Paramphistomosis in West Bengal. Indian Journal of Animal Health, 33 (2), 87-89.

18. Maisonnave, J. (1999) Standardization of a dot immunoperoxidase assay for field diagnosis of Fasciola hepatica infected cattle. Veterinary Parasitology, 85 (4) 259-268.

19. Misra, S. G., Panda, D. N. and Parida, S. (1996) Haematological and histological alterations of immature paramphistomiasis in lambs. Indian Vet. J., 73: 1274-1276.

20. Molina Caballero J. M., Anguiano, A., Ferrer, O., Serrano, E. and Ueeda, A. (1993) Use of an enzyme linked immuno sorbent assay for serodiagnosis of clinical paratuberculosis in goats: study by western blotting of false positive reactions. Rev. Sa. Tech. Off. Int. Epiz., 12, 629-638.
21. Panda, B. K. and Misra, S. C. (1980) Observations on the etiology, clinical pathology and chemotherapy of immature amphistomiasis in buffalo calves. Indian Journal of Animal Health, 29, a 2,131-35.

22. Parsad, A. and Varma, T. K. (1999) On the prevalence and community dominance among paramphistomes infecting domestic ruminants. Journal of Veterinary Parasitology, 13 (2), 129 133.

23. Ristic (1988) Babesiosis of domestic animals and man, CRC Press Boca, Raqton, Florida, pp. 1-227.

24. Rojas, C.A.A., Jex, A.R., Gasser, R.B., Scheerlinck, J.P.Y. (2014) Techniques for the Diagnosis of Fasciola Infections in Animals. Room for Improvement. 1st edn, Advances in Parasitology. 1st edn. Elsevier Ltd.

25. Saheb, S. R. and Hafeez, M. (1995) Haematological changes in buffaloes infected with amphistomiasis. Buffalo Bulletin, 14 (3), 5557.

26. Salimi-Bejestani, McGarry, J.W., Felstead, S., Ortiz, P., Akca, A., and Williams, D.J.L. (2005). Development of an antibody-detection ELISA for Fasciola hepatica and its evaluation against a commercially available test', Research in Veterinary Science, 78(2), pp. 177-181.

27. Santra, A. K. and Pachalag, S. V. (1996) Mortality pattern in crossbred calves. Indian Journal of Animal Sciences, 66 (3), 237-38.

28. Singh, P., Sisodia, B. V. S. and Kunzru, O. N. (1983) Effects of seasons on economic losses due to livestock diseases. Ann. Agric. Res. 4 (1-2), 75-80.

29. Sivajothi, S. and Reddy, B. S. (2014) Immature paramphistomosis in a sheep herd. International Journal of Biological Research. 2(2): 140-142

30. Varma, T. K., Prasad, A., Malviya, H. C. and Dwivedi, P. (1989) Incidence of paramphistome infections in ruminants at Bareilly. Indian Journal of Animal Sciences, 59 (2), 231-234.

31. Zhang, X. L., Duan, J. H., Wang, Y., Kuang, M. S. and Huang, P. S. (2000) Analysis of Paragonimus skrjabini antigen and its application in serodiagnosis. Chinese Journal of Parasitology and Parasitic Diseases,18 (5): 277-281. 